\title{
A raised serum lactate level is an independent predictor of in-hospital mortality in patients with isolated cerebral gunshot wounds
}

\author{
V Y Kong, ${ }^{1} \mathrm{MB} \mathrm{ChB}, \mathrm{MSc}, \mathrm{PhD}, \mathrm{MRCS}(\mathrm{Ed}) ; \mathbf{R}$ D Weale, ${ }^{2} \mathrm{MBBS}$; G L Laing, ${ }^{1} \mathrm{MB} \mathrm{ChB}, \mathrm{PhD}, \mathrm{FCS}(\mathrm{SA}) ; \mathrm{J} \mathrm{L} \mathrm{Bruce},{ }^{1} \mathrm{MB} \mathrm{ChB}, \mathrm{FCS}(\mathrm{SA})$; \\ G V Oosthuizen, ${ }^{1} \mathrm{MB}$ ChB, FCS (SA); B Sartorius, ${ }^{3} \mathrm{PhD}$; P Brysiewicz, ${ }^{3} \mathrm{PhD}$; D L Clarke, ${ }^{1,4} \mathrm{MB} \mathrm{BCh}, \mathrm{MPhil}, \mathrm{MBA}, \mathrm{PhD}, \mathrm{FCS}(\mathrm{SA})$ \\ ${ }^{1}$ Pietermaritzburg Metropolitan Trauma Service, Department of Surgery, Nelson R Mandela School of Medicine, University of KwaZulu-Natal, \\ Durban, South Africa \\ 2 Department of Surgery, Wessex Deanery, UK \\ ${ }^{3}$ Department of Public Health Medicine, School of Nursing and Public Health, University of KwaZulu-Natal, Durban, South Africa \\ ${ }^{4}$ Department of Surgery, Faculty of Health Sciences, University of the Witwatersrand, Johannesburg, South Africa
}

Corresponding author: V Y Kong (victorywkong@yahoo.com)

\begin{abstract}
Background. Cerebral gunshot wounds (CGSWs) represent a highly lethal form of traumatic brain injury, and triaging these patients is difficult. The prognostic significance of the serum lactate level in the setting of CGSWs is largely unknown.

Objectives. To examine the relationship between elevated serum lactate levels and mortality in patients with isolated CGSWs.

Methods. A retrospective review of the regional trauma registry was undertaken at the Pietermaritzburg Metropolitan Trauma Service, South Africa, over a 5-year period from 1 January 2010 to 31 December 2014. All patients with an isolated CGSW were included.

Results. A total of 102 patients with isolated CGSWs were identified. Of these, 92.2\% (94/102) were male. The mean age (standard deviation) was 29 (8) years, and the in-hospital mortality rate was $21.6 \%(22 / 102)$. The mean serum lactate level was significantly higher among non-survivors than among survivors $(6.1 \mathrm{mmol} / \mathrm{L} \mathrm{v.} 1.3 \mathrm{mmol} / \mathrm{L} ; p<0.001)$. Lactate levels among non-survivors were $<2 \mathrm{mmol} / \mathrm{L}$ in $4.5 \%, 2-3.99 \mathrm{mmol} / \mathrm{L}$ in $9.1 \%$, $4-5.99 \mathrm{mmol} / \mathrm{L}$ in $36.4 \%$ and $\geq 6 \mathrm{mmol} / \mathrm{L}$ in $50.0 \%$. The odds ratio for mortality with a lactate level of $4-$ $5.99 \mathrm{mmol} / \mathrm{L}$ was 67 (95\% confidence interval (CI) 1.7 - 2 674.2), while for a lactate level of $\geq 6 \mathrm{mmol} / \mathrm{L}$ it was 1787 (95\% CI 9.0 - 354116.1 ). The serum lactate level accurately predicted mortality even after adjustment for other variables. Based on a receiver operating curve analysis, an optimal cut-off of $3.3 \mathrm{mmol} / \mathrm{L}$ for serum lactate as a predictor for mortality was identified (area under the curve $=0.957$ ).

Conclusions. CGSWs are associated with significant mortality, and a raised serum lactate level appears to be an independent predictor of in-hospital mortality. It is a potentially useful adjunct in the resuscitation room for identifying patients with a very poor prognosis.
\end{abstract}

S Afr Med J 2018;108(5):413-417. DOI:10.7196/SAMJ.2018.v108i5.12837

Cerebral gunshot wounds (CGSWs) are a highly lethal form of traumatic brain injury (TBI), yet there are patients who survive these devastating injuries. ${ }^{[1-3]}$ Triaging these patients is difficult, and accurate early prognostic indicators may help clinicians to make appropriate decisions. ${ }^{[1-5]}$ The prognostic significance of a raised serum lactate level in torso trauma has long been appreciated. In this setting, it is able to guide resuscitation and to a certain extent predict clinical outcome. ${ }^{[6,7]}$ However, the role of lactate in the context of an isolated TBI remains controversial ${ }^{[8-13]}$. Some authors have suggested that elevated serum lactate levels do not correlate with the extent of the cerebral cellular metabolic derangement in these patients, and that the predictive value of serum lactate in TBI is poor. ${ }^{[8-10]}$

Others, however, have shown that the serum lactate level correlates with the severity of TBI. ${ }^{[11,13]}$. Some have proposed that a raised serum lactate level is associated with improved neurological outcomes and lower mortality rates in patients with TBI. It has even been suggested that elevations in serum lactate due to anaerobic metabolism in trauma patients may in fact be neuroprotective..$^{[8]}$

\section{Objectives}

To interrogate the relationship between serum lactate levels and mortality in patients with isolated CGSWs in order to improve prediction of mortality in these patients.

\section{Methods \\ Clinical setting}

This was a retrospective study undertaken at the Pietermaritzburg Metropolitan Trauma Service (PMTS) in Pietermaritzburg, South Africa (SA). Our electronic regional trauma registry was reviewed for the 5-year period from 1 January 2010 to 31 December 2014. Ethics approval for this study and for maintenance of the registry was granted by the Biomedical Research Ethics Committee of the University of KwaZulu-Natal (ref. no. BE 207/09 BCA 221/13). The PMTS provides definitive trauma care to the city of Pietermaritzburg, the capital of KwaZulu-Natal Province. It is one of the largest academic trauma centres in the province and serves as the referral centre for 19 other hospitals in the province, with a total catchment population of over 3 million. Approximately 4000 trauma cases are admitted to the PMTS per annum, with over $50 \%$ being due to penetrating trauma. This is a direct reflection of the high incidence of firearm-related interpersonal violence and criminal activities throughout the entire province.

\section{Criteria}

All patients with single isolated CGSWs were included in the study. Those with concurrent gunshot wounds to other body regions (neck, chest, etc.) were excluded. All patients were managed in accordance with Advanced Trauma Life Support (ATLS) principles. Every patient 
who has sustained a CGSW has a serum lactate level measurement performed as soon as practical after their arrival in the trauma resuscitation room.

\section{Assessment}

Basic demographic data, vital signs on arrival, physical examination findings, Glasgow Coma Score (GCS) and the final clinical outcome were reviewed. In accordance with ATLS, the conventional severity of TBI grading based on the GCS was used: mild (13 - 15), moderate $(9-12)$ and severe $(3-8)$. The serum lactate levels were arbitrarily divided into four categories, 0 - $1.99 \mathrm{mmol} / \mathrm{L}, 2$ - $3.99 \mathrm{mmol} / \mathrm{L}, 4$ $5.99 \mathrm{mmol} / \mathrm{L}$ and $\geq 6 \mathrm{mmol} / \mathrm{L}$, for the purposes of comparison.

\section{Statistical analysis}

The data were processed and analysed using Stata 13.0 (StataCorp, USA). Any associations between admission GCS category, serum lactate and categorical explanatory variables were assessed using Pearson's $\chi^{2}$ test, or Fisher's exact test if an expected cell count was fewer than 5 observations. Comparison of means of continuous markers by GCS admission category was assessed using one-way analysis of variance. Correlations between GCS admission score and serum lactate were assessed using Spearman's rank correlation coefficient.

\section{Results}

Description of the patient cohort

During the 5-year study period, 102 patients with isolated CGSWs were treated at our institution. Of these, 92.2\% (94/102) were male and the mean (standard deviation (SD)) age was 29 (8) years. Most of the injuries $(92.3 \%, 94 / 102)$ were related to interpersonal violence (assault). The remaining $7.8 \%$ (8/102) were attempted suicides; all these patients were male. The mean (SD) values of physiological parameters on arrival were as follows: heart rate $85(24) / \mathrm{min}$, systolic blood pressure $124(22) \mathrm{mmHg}$, temperature $36(1)^{\circ} \mathrm{C}$. The mean (SD) GCS on arrival was 12 (5). Thirty percent (31/102) of all patients had visible brain matter oozing from the wound. All 102 patients underwent computed tomography (CT) scans, of which $21.6 \%(22 / 102)$ revealed a bullet in situ. Neurosurgical intervention was required in $30.4 \%$ of cases (31/102); 28 (90.3\%) of these 31 patients underwent debridement and/or elevation of a depressed skull fracture, and 3 required formal craniotomy for evacuation of a haematoma. Of the 102 patients, $21.6 \%(22 / 102)$ died during the admission. The remaining 80 patients $(78.4 \%)$ survived to discharge. The mean (SD) GCS on discharge of all 80 survivors was 14 .

\section{CGCS v. lactate levels}

Of the 102 patients, $19.6 \%(20 / 102)$ had a GCS of $3-8$ on admission, $19.6 \%(20 / 102)$ a GCS of $9-12$ and $60.8 \%(62 / 102)$ a GCS of $12-15$. Table 1 summarises the demographics, clinical parameters and mean serum lactate level for each of these three severity groups. There was a significant difference in mean lactate level between the three groups, the level increasing as severity as determined by the GCS increased (mild: lactate $1.1 \mathrm{mmol} / \mathrm{L}$, moderate: lactate $2.6 \mathrm{mmol} / \mathrm{L}$, severe: lactate $5.6 \mathrm{mmol} / \mathrm{L} ; p<0.001)$. This is shown in Table 2. A strong

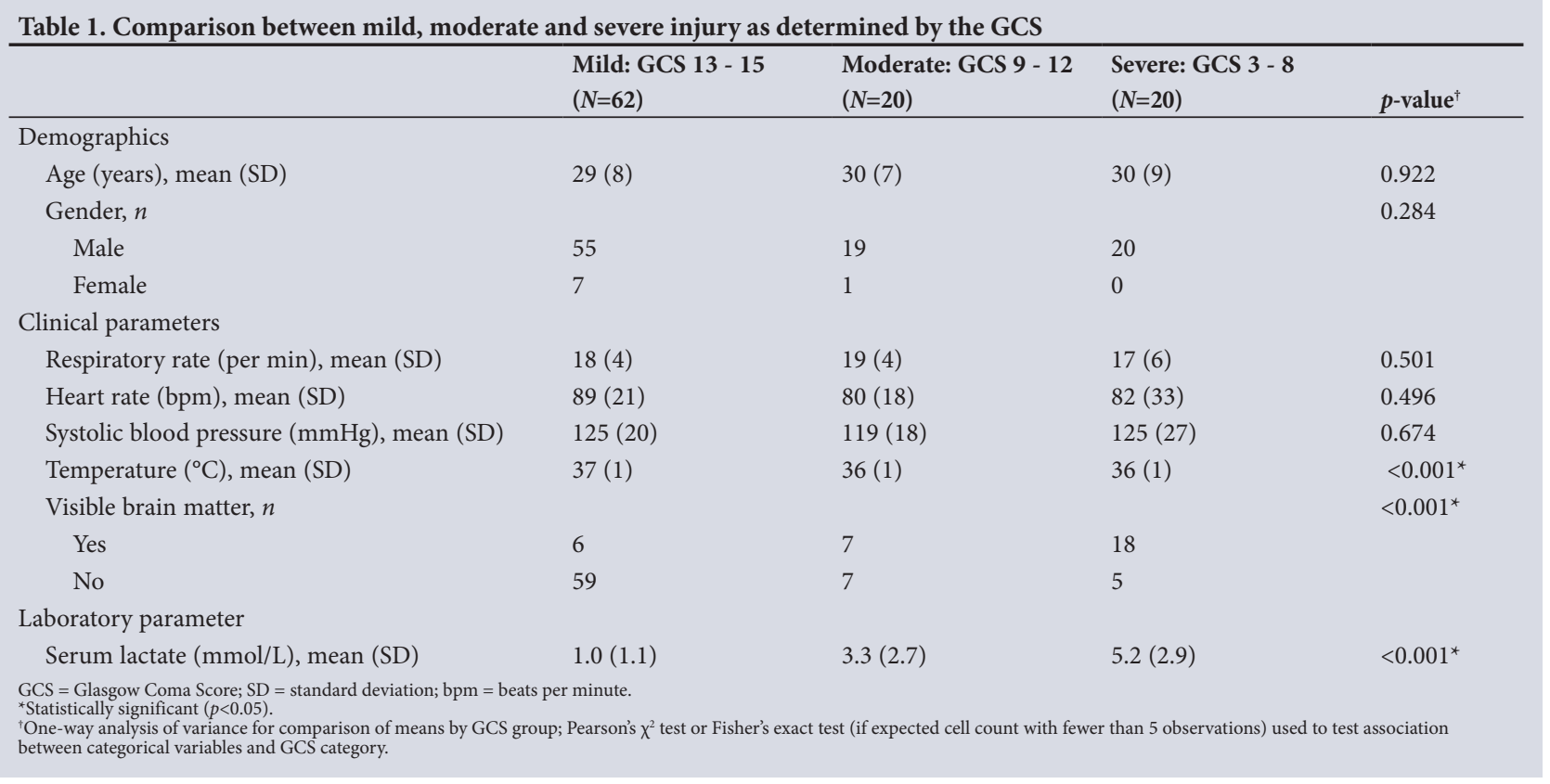

Table 2. The four categories of serum lactate levels in relation to GCS

\begin{tabular}{|c|c|c|c|c|}
\hline Lactate level (mmol/L) & Mild: GCS 13 - $15(N=62), n(\%)$ & Moderate: GCS 9 - $12(N=20), n(\%)$ & Severe: GCS 3 - $8(N=20), n(\%)$ & $p$-value ${ }^{\dagger}$ \\
\hline $0-1.99$ & $54(87.1)$ & $10(50.0)$ & $2(10.0)$ & \multirow{4}{*}{$<0.001^{\times}$} \\
\hline $2-3.99$ & $4(6.5)$ & $5(25.0)$ & $3(15.0)$ & \\
\hline $4-5.99$ & $3(4.8)$ & $3(15.0)$ & $5(25.0)$ & \\
\hline$\geq 6$ & $1(1.6)$ & $2(10.0)$ & $10(50.0)$ & \\
\hline $\begin{array}{l}\text { GCS }=\text { Glasgow Coma Score. } \\
{ }^{*} \text { Statistically significant }(p<0.05) \text {. } \\
\text { 'Fisher's exact test. }\end{array}$ & & & & \\
\hline
\end{tabular}


inverse (negative) correlation was noted between serum lactate and admission GCS. The mean serum lactate level among non-survivors was significantly higher than that among survivors $(6.1 \mathrm{mmol} / \mathrm{L} \mathrm{v} .1 .3$ $\mathrm{mmol} / \mathrm{L} ; p<0.001$ ) (Fig. 1).

\section{Serum lactate levels and mortality}

There was a direct correlation between increasing serum lactate levels and mortality. Table 3 summarises the differences in demographics, clinical parameters and serum lactate levels between sur-

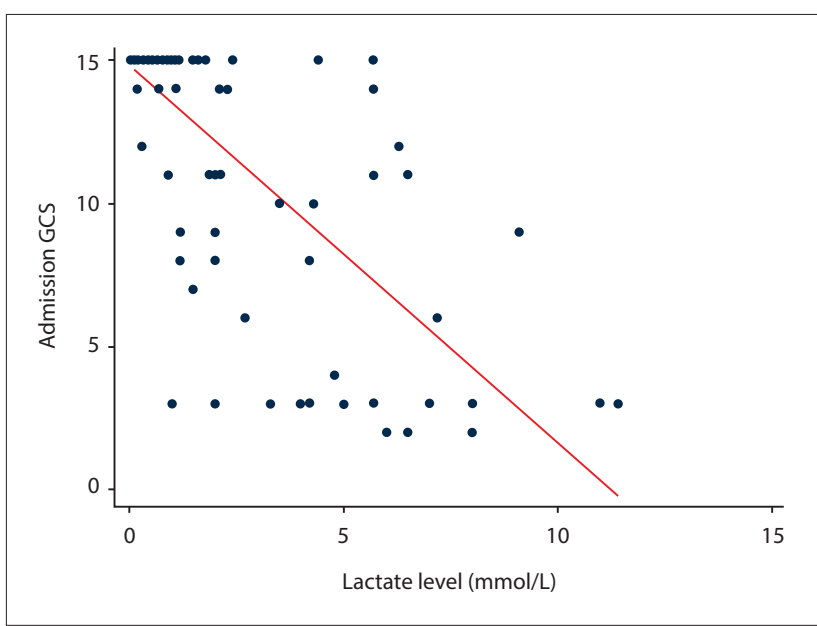

Fig. 1. Inverse correlation between serum lactate level and admission GCS. (GCS = Glasgow Coma Score. $)$ vivors and non-survivors. This relationship is represented graphically in Figs 2 and 3. Both graphs demonstrate a direct relationship between increasing serum lactate levels and increasing mortality. An optimal breakpoint for serum lactate of $3.3 \mathrm{mmol} / \mathrm{L}$ for mortality prediction was identified using a positive predictive value (PPV) optimisation procedure for the receiver operating characteristic (ROC) curve (Fig. 4). The area under the curve for this cut-off was 0.957 (95\% CI 0.913 - 1.001), which is well above the accepted cut-off of 0.8 for a good predictor. This optimal breakpoint yielded a high sensitivity $(95 \%, 95 \%$ CI 77 - 99), specificity (94\%, 95\% CI 86 - 98), PPV (81\%, 95\% CI 63 - 99) and negative predictive value (99\%, 95\% CI 92 - 99). A direct comparison was made between survivors (80/102) and non-survivors (22/102). Table 4 shows how mortality increased with increasing serum lactate levels.

\section{Discussion}

CGSWs are a highly lethal form of TBI, and the severity of the injury strongly determines the outcome. The GCS is a highly successful and tried-and-tested clinical scoring system for blunt TBI. It is simple, elegant and repeatable, and separates TBI into the three broad categories of mild, moderate and severe. Although an elevated serum lactate level is a well-recognised marker of severity in torso trauma, its significance in TBI is unclear. ${ }^{[6-12]}$ Our data suggested a close correlation between increased serum lactate levels and lower GCS. In addition, both these scoring systems correlate with increasing mortality.

Lactate is a waste product of anaerobic metabolism and reflects cellular disruption secondary to hypoperfusion and shock. It is a

Table 3. Baseline comparison between non-survivors and survivors

\begin{tabular}{|c|c|c|c|}
\hline & Non-survivors $(N=22)$ & Survivors $(N=80)$ & $p$-value \\
\hline \multicolumn{4}{|l|}{ Demographics } \\
\hline Age (years), mean (SD) & $30(10)$ & $29(8)$ & 0.7943 \\
\hline Gender, $n(\%)$ & & & 0.196 \\
\hline Male & $22(100.0)$ & $72(90.0)$ & \\
\hline Female & $0(0)$ & $8(10.0)$ & \\
\hline \multicolumn{4}{|l|}{ Clinical parameters, mean (SD) } \\
\hline Respiratory rate (per min) & $17(6)$ & $18(4)$ & 0.3915 \\
\hline Heart rate $(\mathrm{bpm})$ & $76(30)$ & $87(21)$ & $0.0336^{*}$ \\
\hline Systolic blood pressure $(\mathrm{mmHg})$ & $124(29)$ & $124(19)$ & 0.608 \\
\hline Temperature $\left({ }^{\circ} \mathrm{C}\right)$ & $36(1)$ & $37(1)$ & $0.0012^{*}$ \\
\hline Visible brain matter & & & $<0.001^{*}$ \\
\hline Yes & $17(77.3)$ & $14(17.5)$ & \\
\hline No & $5(22.7)$ & $66(82.5)$ & \\
\hline Admission GCS & $4(3)$ & $14(2)$ & $<0.001^{*}$ \\
\hline \multicolumn{4}{|l|}{ Laboratory parameter, mean (SD) } \\
\hline Serum lactate $(\mathrm{mmol} / \mathrm{L})$ & $6.1(2.5)$ & $1.3(1.3)$ & $<0.001^{*}$ \\
\hline
\end{tabular}

Table 4. Mortality according to serum lactate level

\begin{tabular}{|c|c|c|c|c|}
\hline Lactate level (mmol/L) & Non-survivors $(N=22), n(\%)$ & Survivors $(N=80), n(\%)$ & OR $(95 \% \mathrm{CI})^{\dagger}$ & $p$-value ${ }^{\dagger}$ \\
\hline$<2$ & $1(4.5)$ & $65(81.3)$ & 1 (ref) & - \\
\hline $2-3.99$ & $2(9.1)$ & $10(12.5)$ & $1.2(0-84)$ & 0.931 \\
\hline $4-5.99$ & $8(36.4)$ & $4(5.0)$ & $66.8(1.7-2674.2)$ & $0.026^{*}$ \\
\hline$\geq 6$ & $11(50.0)$ & $1(1.3)$ & $1786.9(9.0-354116.1)$ & $0.006^{*}$ \\
\hline
\end{tabular}




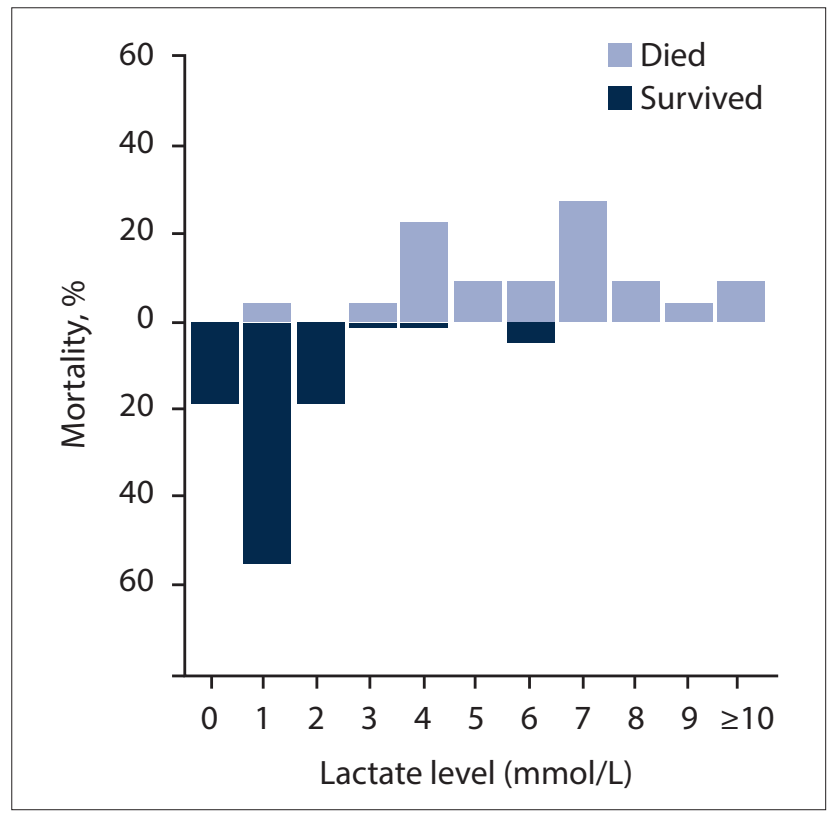

Fig. 2. Correlation between serum lactate level and mortality.

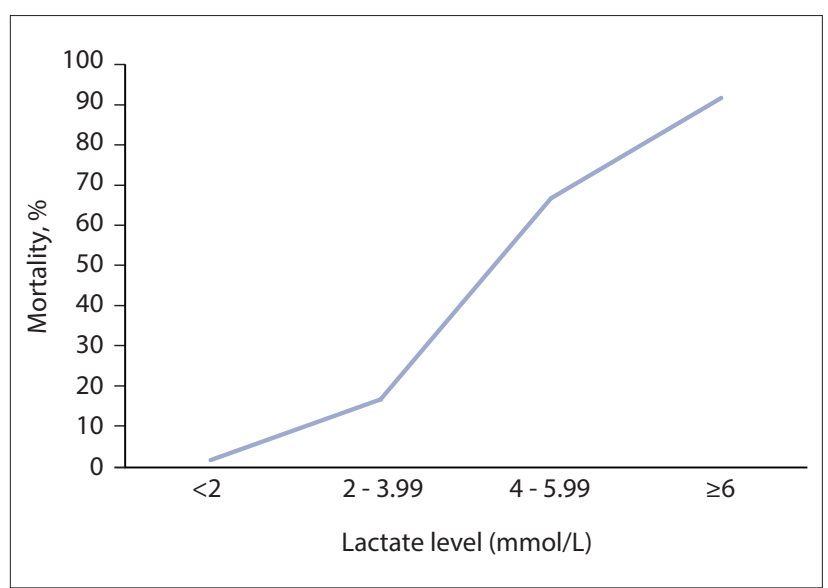

Fig. 3. Mortality rate according to increasing lactate level category.

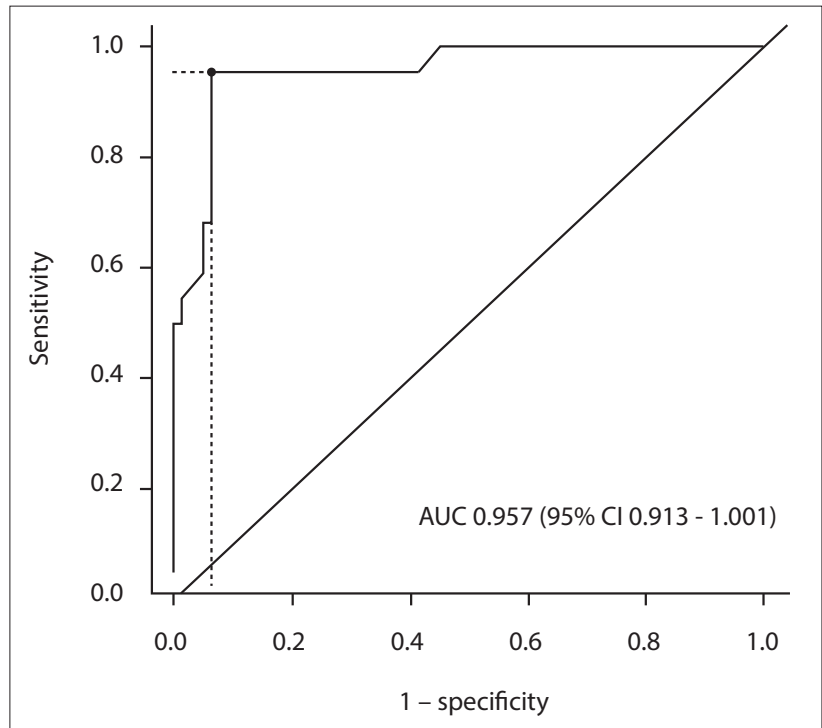

Fig. 4. ROC curve (criterion: ROC01) for optimal breakpoint identification of serum lactate level for mortality prediction. $(R O C=$ receiver operating characteristic; $A U C=$ area under the curve.) better marker of shock states than vital signs, which may only become deranged late in the development of such a state. ${ }^{[6,7]}$ In the context of TBI, some authors have suggested that elevated serum lactate levels reflect a general state of global hypoperfusion rather than cerebral metabolic derangement per se. ${ }^{[8-10]}$ In a large series of 555 consecutive cases of isolated TBI, Cureton et al. ${ }^{[8]}$ demonstrated that the serum lactate level was closely correlated with severity of TBI. However, they noted that a raised serum lactate level was associated with improved neurological outcomes and lower mortality rates. They went so far as to suggest that elevations in lactate due to anaerobic metabolism in trauma patients may be neuroprotective. Experimental data support this suggestion. ${ }^{[11-13]}$

The only study on the relationship between TBI and serum lactate in SA to date was from Milpark Hospital in Johannesburg. ${ }^{\left[{ }^{[5]}\right.}$ In this study of 72 consecutive cases of isolated CGSWs, it was noted that the mean lactate level was higher in non-survivors than survivors ( 6.7 v. $2.7 \mathrm{mmol} / \mathrm{L}$ ). In the present study, we have demonstrated that elevated serum lactate levels are predictive of increased in-hospital mortality. Using $3.3 \mathrm{mmol} / \mathrm{L}$ as a cut-off value, the odds of mortality are well over 300 . We have also demonstrated that mortality increases dramatically as the serum lactate level rises. This remains significant even after adjusting for other variables and appears to be an independent predictor of in-hospital mortality. We consider that measurement of serum lactate levels in patients with a CGSW may potentially be useful as a predictor of mortality, especially if used in conjunction with other clinical features such as the GCS and the presence of exposed brain tissue. However, our sample sizes were small and the results should be interpreted with caution.

\section{Conclusions}

CGSWs are associated with significant mortality and a raised serum lactate level appears to be an independent predictor of in-hospital mortality. Serum lactate levels are closely correlated with the severity of penetrating TBI following a CGSW as determined by the GCS. There is an inverse relationship between admission GCS and serum lactate level. Serum lactate levels may well be a useful adjunct in determining the severity of TBI post CGSW. Further studies are required to assess the long-term neuropsychological outcomes in this injury subset in relation to our findings.

\section{Acknowledgements. None.}

Author contributions. VYK: data collection, statistics and writing of article; GLL, JLB, GVO, RDW, BS, PB and DLC: writing of article and production of tables.

Funding. Article publication fees paid by the University of KwaZulu-Natal. Conflicts of interest. None.

1. Joseph B, Aziz H, Pandit V, et al. Improving survival rates after civilian gunshot wounds to the brain. J Am Coll Surg 2014;218(1):58-65. https://doi.org/10.1016/j.jamcollsurg.2013.08.018

2. Stone IL, Lichtor T, Fitzgerald LF. Gunshot wounds to the head in civilian practice. Neurosurgery . Stone JL, Lichtor T, Fitzgerald LF. Gunshot wounds to the head in civilian
1995;37(6):1104-1112. https://doi.org/10.1097/00006123-199512000-00010

3. Aarabi B, Tofighi B, Kufera JA, et al. Predictors of outcome in civilian gunshot wounds to the head. J Neurosurg 2014;120(5):1138-1146. https://doi.org/10.3171/2014.1.JNS131869

4. Martins RS, Siqueira MG, Santos MT, Zanon-Collange N, Moraes OJ. Prognostic factors and treatment of penetrating gunshot wounds to the head. Surg Neurol 2003;60(2):98-104. https://doi.org/10.1016/ s0090-3019(03)00302-1

5. Glapa M, Zorio M, Snyckers FD, et al. Gunshot wounds to the head in civilian practice. Am Surg 2009; 75(3):223-226.

6. Régnier MA, Raux M, le Manach Y, et al. Prognostic significance of blood lactate and lactate clearance in trauma patients. Anesthesiology 2012;117(6):1276-1288. https://doi.org/10.1097/ ALN.0b013e318273349d

7. Odom SR, Howell MD, Silva GS, et al. Lactate clearance as a predictor of mortality in trauma patients. J Trauma Acute Care Surg 2013;74(4):999-1004. https://doi.org/10.1097/TA.0b013e3182858a3e

8. Cureton EL, Kwan RO, Dozier KC, Sadjadi J, Pal JD, Victorino GP. A different view of lactate in trauma patients: Protecting the injured brain. J Surg Res 2010;159(1):468-473. https://doi.org/10.1016/j. jss.2009.04.020

9. Bouzat P, Oddo M. Lactate and the injured brain: Friend or foe? Curr Opin Crit Care 2014;20(2):133140. https://doi.org/10.1097/MCC.0000000000000072 
10. Patet C, Suys T, Carteron L, Oddo M. Cerebral lactate metabolism after traumatic brain injury. Curr Neurol Neurosci Rep 2016;16(4):31. https://doi.org/10.1007/s11910-016-0638-5

11. Carpenter KL, Jalloh I, Hutchinson PJ. Glycolysis and the significance of lactate in traumatic brain injury. Front Neurosci 2015;9:112. https://doi.org/10.3389/fnins.2015.00112

12. Jalloh I, Helmy A, Shannon RJ, et al. Lactate uptake by the injured human brain: Evidence from an arteriovenous gradient and cerebral microdialysis study. Neurotrauma 2013;30(24):2031-2037. https:// doi.org/10.1089/neu.2013.2947
13. Glenn TC, Martin NA, Horning MA, et al. Lactate: Brain fuel in human traumatic brain injury: A comparison with normal healthy control subjects. J Neurotrauma 2015;32(11):820-832. https://doi org/10.1089/neu.2014.3483

Accepted 11 December 2017. 